Original Article

\title{
IMPACT OF SOLVENT TYPES ON ANTIMICROBIAL ACTIVITIES OF ROOT EXTRACT OF CAESARIA TOMENTOSA
}

\author{
GAURI PAI ANGLE ${ }^{*}$, YOGITA SARDESSAI ${ }^{2}$
}

1Department of Pharmacognosy P. E. S's Rajaram and Tarabai Bandekar College of Pharmacy, Ponda-Goa, ${ }^{2}$ Goa College of Pharmacy, Panjim-Goa

Email: gauri.angle@gmail.com

Received: 16 Dec 2018 Revised and Accepted: 15 Feb 2019

\begin{abstract}
Objective: The study deals with the antimicrobial activity of five solvent extracts of roots of Caesaria tomentosa against seven microorganisms: two gram-positive (Staphylococcus aureus and Bacillus subtilis), three gram-negative bacteria (Escherichia coli, Pseudomonas aeruginosa and Salmonella typhimrium) and two fungal strains (Candida albicans and Aspergillus niger).

Methods: Roots of $C$. tomentosa were extracted with different solvents(n-hexane, ethanol, chloroform, acetone and water) and were subjected to antibacterial as well as antifungal screening by Well Diffusion Method. The Minimum Inhibitory Concentration(MIC) was also performed by two-fold dilution.

Results: The maximum inhibition zone at $50 \mu \mathrm{g} / \mathrm{ml}$ concentration of n-hexane was $32 \mathrm{~mm}$. These indicate that some active substances in $C$. tomentosa dissolved in varying degrees in the five solvents. The MIC for $\mathrm{n}$-hexane was $1.6 \mu \mathrm{g} / \mathrm{ml}$ for $S$. aureus leading to a conclusion that the $\mathrm{n}$ hexane extract was found to be the most potent.
\end{abstract}

Conclusion: All extracts were very effective against $S$. aureus. As for the solvents, the n-hexane extract had the best inhibitory effect among five solvents tested.

Keywords: Antimicrobial activity, Disc diffusion, Minimum Inhibitory Concentration

(C) 2019 The Authors. Published by Innovare Academic Sciences Pvt Ltd. This is an open access article under the CC BY license (http://creativecommons.org/licenses/by/4.0/) DOI: http://dx.doi.org/10.22159/ijpps.2019v11i4.31398

\section{INTRODUCTION}

Bacteria have evolved numerous defences against the antimicrobial agent and drug resistance in pathogen is on rise. This is due to rapid development of multi-drug resistance, limited anti-bacterial spectrum and adverse effects of available anti-microbial agents. This necessitates the search for new antimicrobials with diverse structures and novel mechanism of action.

Plants have been used as a rich source of many natural products used for the treatment of diseases and their secondary metabolite constituents are the sources of important modern drugs such as atropine, codeine, digoxin, morphine, quinine and vincristine.

In ancient times South American and Asian countries used different Casearia species as traditional medicines. Casearia (family Salicaceae) has huge pharmacological importance with studies proving that the crude extracts and isolated compounds from this genus showed hypoglycemic, antioxidant, antiulcer, anti-inflammatory activities, and antimicrobial as well as anti-snake venom property [1].

Casearia tomentosa, it is a small tree up to $50-80 \mathrm{~cm}$ girth and $7 \mathrm{~m}$ tall. Its common name is Chilla. Different parts of $C$. tomentosa is traditionally claimed for its medicinal importance like in ulcers, dropsy, fissures, colic pain in the abdomen, malarial fever, tonsillitis pain, wounds, and in severe bone fractures as a plaster [2-4].

The literature survey revealed that $C$. tomentosa is still an under explored species [5]. The aim of this study was to study the impact of solvent types on antimicrobial activities of root extract of $C$. tomentosa.

\section{MATERIALS AND METHODS}

Chemicals required

n-hexane, chloroform, ethanol, acetone and distilled water.

\section{Collection of plant species}

The roots of $C$. tomentosa were collected from wild forests of North Goa. The collected plant material was air-dried under shade and dried roots were crushed into powder by the blender.

\section{Preparation of extracts}

Ten grams of dried root powder of $C$. tomentosa was placed in five 500-ml Erlenmeyer flasks. Subsequently, a 200-ml each of five solvents, namely: $\mathrm{n}$-hexane, chloroform, ethanol, acetone and water were separately placed accordingly. After addition of each solvent, the corresponding mixtures which had a final concentration of $5 \%$, were shaken vigorously for $72 \mathrm{hr}$. The crude extracts were filtered under vacuum and filtrates were evaporated to dryness [6].

\section{Microorganisms}

In the present study, ethanolic extract of the roots of $C$. tomentosa was tested for antimicrobial activity by well diffusion method. Five bacterial strains used included two gram-positive-Staphylococcus aureus (S. aureus) (ATCC 6538P) and Bacillus subtilis (B. subtilis)(ATCC 6633) and three gram-negative bacteria-Escherichia coli (E. coli) (ATCC 35218), Pseudomonas aeruginosa (P. aeruginosa) (ATCC 19429) and Salmonella typhimurium (S. typhimurium) (ATCC 23564). Two fungal strains, Candida albicans(C. albicans) (NCIM No.10231) and Aspergillus niger (A. niger) (NCIM No.10864) were used. All the bacterial strains and fungal strains were maintained on Nutrient Agar and Saboraud's Dextrose Agar respectively and were freshly subcultured for 24-48 h at $37{ }^{\circ} \mathrm{C}$ and $25^{\circ} \mathrm{C}$ respectively. All strains were procured from National chemical laboratory (NCL) Pune.

\section{Antimicrobial agents}

Ciprofloxacin $(10 \mu \mathrm{g} / \mathrm{ml})$ for antibacterial studies and metronidazole $(10 \mu \mathrm{g} / \mathrm{ml})$ were included in the study as standard reference drugs

\section{Antimicrobial activity}

The extracts of roots $C$. tomentosa was subjected to antibacterial as well as antifungal screening by Well Diffusion Method (Cup Plate Method) [7]. Mueller Hinton Agar/Broth(Hi Media) and Sabouraud's Dextrose Agar/Broth(Hi Media) were used as the seed medium for the antibacterial and antifungal screening respectively.

The Minimum Inhibitory Concentration (MIC) was performed by two-fold dilution of the test extract in the respective medium under 
sterile conditions [8-11]. The inoculums were verified by streaking on specific medium for colony identification and purification. Appropriate controls were maintained. The plates were observed visually and the diameter of zones was measured using mm scale. The activity was indicated by the presence of clear zones around the well size. These studies were performed in triplicate and mean values were tabulated to check the effectiveness of the procedure. The MIC was determined by the turbidimetric method by measuring the Optical Density at $600 \mathrm{~nm}$ using Elico colorimeter (Filter No. 60).

\section{Statistical analysis}

The data recorded during the course of the investigation were statistically analysed by two-way classification method (Anova: two factor without replication) and the conclusion was drawn on the basis of analysis of variance technique. The calculated value of $F$ was compared with the tabulated value at $5 \%$ and $1 \%$ level of significance for appropriate degrees of freedom.

\section{RESULTS}

The results of present study revealed that all extracts were very effective against $S$. aureus showing maximum inhibition zone at $50 \mu \mathrm{g} / \mathrm{ml}$ concentration of $\mathrm{n}$-hexane extract was $32 \mathrm{~mm}$ among the five bacterial strains (table 1).

The results also indicated that the extracts of the roots of $C$ tomentosa showed significant antifungal activity against both $A$. niger and $C$. albicans. (table 2) Generally, the overall impact of extracts against the seven microorganisms was clearly shown where the effects of extracts increase with the increase of extract concentrations.

Table 1: Antibacterial activity of different solvent extracts by well diffusion method

\begin{tabular}{|c|c|c|c|c|c|c|c|c|c|c|c|}
\hline \multirow[t]{3}{*}{ C. tomentosa extract } & \multirow{3}{*}{$\begin{array}{l}\text { Extract concentration } \\
(\mu \mathrm{g} / \mathrm{ml})\end{array}$} & \multicolumn{10}{|c|}{ Diameter of zone of inhibition in $\mathrm{mm}$} \\
\hline & & \multicolumn{2}{|c|}{ S. aureus } & \multicolumn{2}{|c|}{ B. subtilis } & \multicolumn{2}{|c|}{ P. aeruginosa } & \multicolumn{2}{|l|}{ E. coli } & \multicolumn{2}{|c|}{ S. typhimurium } \\
\hline & & Mean & SEM & Mean & SEM & Mean & SEM & Mean & SEM & Mean & SEM \\
\hline \multirow[t]{2}{*}{ n-hexane } & 25 & 18 & \pm 0.0 & 10 & \pm 0.5 & 13 & \pm 0.5 & 8 & \pm 0.0 & 6 & \pm 0.5 \\
\hline & 50 & 32 & \pm 0.5 & 23 & \pm 0.5 & 28 & \pm 0.0 & 18 & \pm 0.0 & 14 & \pm 0.5 \\
\hline \multirow[t]{2}{*}{ Ethanol } & 25 & 12 & \pm 0.5 & 11 & \pm 0.0 & 7 & \pm 0.5 & 8 & \pm 0.5 & 6 & \pm 0.0 \\
\hline & 50 & 23 & \pm 0.0 & 17 & \pm 0.0 & 11 & \pm 0.0 & 15 & \pm 0.5 & 13.5 & \pm 0.0 \\
\hline \multirow[t]{2}{*}{ Chloroform } & 25 & 15 & \pm 0.0 & 11 & \pm 0.5 & 10 & \pm 0.5 & 14 & \pm 0.0 & 7 & \pm 0.5 \\
\hline & 50 & 26 & \pm 0.5 & 18 & \pm 0.5 & 23 & \pm 0.0 & 22 & \pm 0.5 & 17 & \pm 0.5 \\
\hline \multirow[t]{2}{*}{ Acetone } & 25 & 13 & \pm 0.0 & 10 & \pm 0.0 & 11 & \pm 0.0 & 8 & \pm 0.0 & 9 & \pm 0.0 \\
\hline & 50 & 21 & \pm 0.5 & 24 & \pm 0.5 & 18 & \pm 0.5 & 14 & \pm 0.5 & 11 & \pm 0.5 \\
\hline \multirow[t]{2}{*}{ Water } & 25 & 13 & \pm 0.5 & 10 & \pm 0.0 & 8 & \pm 1.5 & 11 & \pm 0.5 & 7 & \pm 1.5 \\
\hline & 50 & 18 & \pm 0.5 & 17 & \pm 0.5 & 16 & \pm 0.0 & 16 & \pm 0.0 & 11 & \pm 0.0 \\
\hline Standard & 10 & 18 & \pm 0.5 & 27 & \pm 0.5 & 32 & \pm 0.0 & 24 & \pm 0.0 & 22 & \pm 0.5 \\
\hline
\end{tabular}

$\mathrm{n}=3$, data is given in mean $\pm \operatorname{SEM}$ (standard error of mean).

Table 2: Antifungal activity of different solvent extracts by well diffusion

\begin{tabular}{|c|c|c|c|c|c|}
\hline \multirow[t]{3}{*}{ C. tomentosa extract } & \multirow[t]{3}{*}{ Extract concentration $(\mu \mathrm{g} / \mathrm{ml})$} & \multicolumn{4}{|c|}{ Diameter of zone of inhibition in $\mathrm{mm}$} \\
\hline & & \multicolumn{2}{|l|}{ A. niger } & \multicolumn{2}{|c|}{ C. albicans } \\
\hline & & Mean & SEM & Mean & SEM \\
\hline \multirow[t]{2}{*}{ n-hexane } & 25 & 18 & \pm 0.0 & 21 & \pm 0.5 \\
\hline & 50 & 24 & \pm 0.0 & 26 & \pm 0.0 \\
\hline \multirow[t]{2}{*}{ ethanol } & 25 & 10 & \pm 0.5 & 8 & \pm 0.0 \\
\hline & 50 & 14 & \pm 0.5 & 9 & \pm 0.0 \\
\hline \multirow[t]{2}{*}{ chloroform } & 25 & 14 & \pm 0.0 & 16 & \pm 0.5 \\
\hline & 50 & 17 & \pm 0.5 & 19 & \pm 0.0 \\
\hline \multirow[t]{2}{*}{ acetone } & 25 & 13 & \pm 1.5 & 9 & \pm 1.5 \\
\hline & 50 & 20 & \pm 0.0 & 15 & \pm 0.0 \\
\hline \multirow[t]{2}{*}{ Water } & 25 & 17 & \pm 0.0 & 12 & \pm 0.0 \\
\hline & 50 & 21 & \pm 0.0 & 18 & \pm 0.5 \\
\hline standard & 10 & 32 & \pm 0.5 & 28 & \pm 0.5 \\
\hline
\end{tabular}

$n=3, n=3$, data is given in mean $\pm \operatorname{SEM}($ standard error of mean)

In statistical analysis it was seen that the calculated $\mathrm{F}$ value is higher in almost all cases than the tabulated $\mathrm{F}$ value at $5 \%$ and $1 \%$ level of significance indicating that there is significant variation seen in between the strains (both antibacterial and antifungal) as well as different solvents types used for present study (table 3, 4,5 and 6 of statistical analysis).

Table 3: Statistical analysis of the antibacterial activity of solvent extract (25micro gram/ml)

\begin{tabular}{|c|c|c|c|c|c|}
\hline & S. aureus & B. subtilis & P aeuginosa & E. coli & S. typhimurium \\
\hline $\mathrm{n}$ hexane & 18 & 10 & 13 & 8 & 6 \\
\hline Ethanol & 12 & 11 & 7 & 8 & 6 \\
\hline Chloroform & 15 & 11 & 10 & 14 & 7 \\
\hline Acetone & 13 & 10 & 11 & 8 & 9 \\
\hline water & 13 & 10 & 8 & 11 & 7 \\
\hline \multicolumn{6}{|c|}{ Anova: Two-Factor Without Replication } \\
\hline SUMMARY & & Count & Sum & Average & Variance \\
\hline Row 1 & & 5 & 55 & 11 & 22 \\
\hline Row 2 & & 5 & 44 & 8.8 & 6.7 \\
\hline Row 3 & & 5 & 57 & 11.4 & 10.3 \\
\hline
\end{tabular}




\begin{tabular}{|c|c|c|c|c|c|c|c|}
\hline Row 4 & & 5 & 51 & 10.2 & & 3.7 & \\
\hline Row 5 & & 5 & 49 & 9.8 & & 5.7 & \\
\hline Column 1 & & 5 & 71 & 14.2 & & 5.7 & \\
\hline Column 2 & & 5 & 52 & 10.4 & & 0.3 & \\
\hline Column 3 & & 5 & 49 & 9.8 & & 5.7 & \\
\hline Column 4 & & 5 & 49 & 9.8 & & 7.2 & \\
\hline Column 5 & & 5 & 35 & 7 & & 1.5 & \\
\hline \multicolumn{8}{|l|}{ ANOVA } \\
\hline Source of Variation & $S S$ & $d f$ & $M S$ & $F$ & $P$-value & & $F_{\text {crit }}$ \\
\hline Rows & 20.96 & 4 & 5.24 & 1.382586 & 0.284151 & & 3.006917 \\
\hline Columns & 132.96 & 4 & 33.24 & 8.770449 & 0.000602 & & 3.006917 \\
\hline Error & 60.64 & 16 & 3.79 & & & & \\
\hline Total & 214.56 & 24 & & & & & \\
\hline
\end{tabular}

Sum of squares (SS), the degree of freedom (df), mean of squares (MS), Probability Valve (P-value)

Table 4: Statistical analysis antibacterial activity of solvent extract (50 microgram/ml)

\begin{tabular}{|c|c|c|c|c|c|c|c|}
\hline & S. aureus & B. subtilis & & Paeuginosa & & E. coli & S. typhimurium \\
\hline $\mathrm{n}$ hexane & 32 & 23 & & 28 & & 18 & 14 \\
\hline Ethanol & 23 & 17 & & 11 & & 15 & 13.5 \\
\hline Chloroform & 26 & 18 & & 23 & & 22 & 17 \\
\hline Acetone & 21 & 24 & & 18 & & 14 & 11 \\
\hline water & 18 & 17 & & 16 & & 16 & 11 \\
\hline \multicolumn{8}{|c|}{ Anova: Two-Factor Without Replication } \\
\hline SUMMARY & & \multicolumn{2}{|c|}{ Count } & \multicolumn{2}{|l|}{ Sum } & Average & Variance \\
\hline Row 1 & & \multicolumn{2}{|l|}{5} & \multicolumn{2}{|l|}{115} & 23 & 53 \\
\hline Row 2 & & \multicolumn{2}{|l|}{5} & \multicolumn{2}{|l|}{79.5} & 15.9 & 20.55 \\
\hline Row 3 & & \multicolumn{2}{|l|}{5} & \multicolumn{2}{|l|}{106} & 21.2 & 13.7 \\
\hline Row 4 & & \multicolumn{2}{|l|}{5} & \multicolumn{2}{|l|}{88} & 17.6 & 27.3 \\
\hline Row 5 & & \multicolumn{2}{|l|}{5} & \multicolumn{2}{|l|}{78} & 15.6 & 7.3 \\
\hline Column 1 & & \multicolumn{2}{|l|}{5} & \multicolumn{2}{|l|}{120} & 24 & 28.5 \\
\hline Column 2 & & \multicolumn{2}{|l|}{5} & \multicolumn{2}{|l|}{99} & 19.8 & 11.7 \\
\hline Column 3 & & \multicolumn{2}{|l|}{5} & \multicolumn{2}{|l|}{96} & 19.2 & 42.7 \\
\hline Column 4 & & \multicolumn{2}{|l|}{5} & \multicolumn{2}{|l|}{85} & 17 & 10 \\
\hline Column 5 & & \multirow{2}{*}{\multicolumn{2}{|c|}{5}} & \multicolumn{2}{|l|}{66.5} & 13.3 & 6.2 \\
\hline ANOVA & & & & & & & \\
\hline Source of Variation & $S S$ & & $d f$ & $M S$ & $F$ & P-value & F crit \\
\hline Rows & 216.96 & & 4 & 54.24 & 4.83638 & 0.009483 & 3.006917 \\
\hline Columns & 307.96 & & 4 & 76.99 & 6.864913 & 0.002043 & 3.006917 \\
\hline Error & 179.44 & & 16 & 11.215 & & & \\
\hline Total & 704.36 & & 24 & & & & \\
\hline
\end{tabular}

Table 5: Statistical analysis antifungal activity of solvent extract (25micro gram/ml)

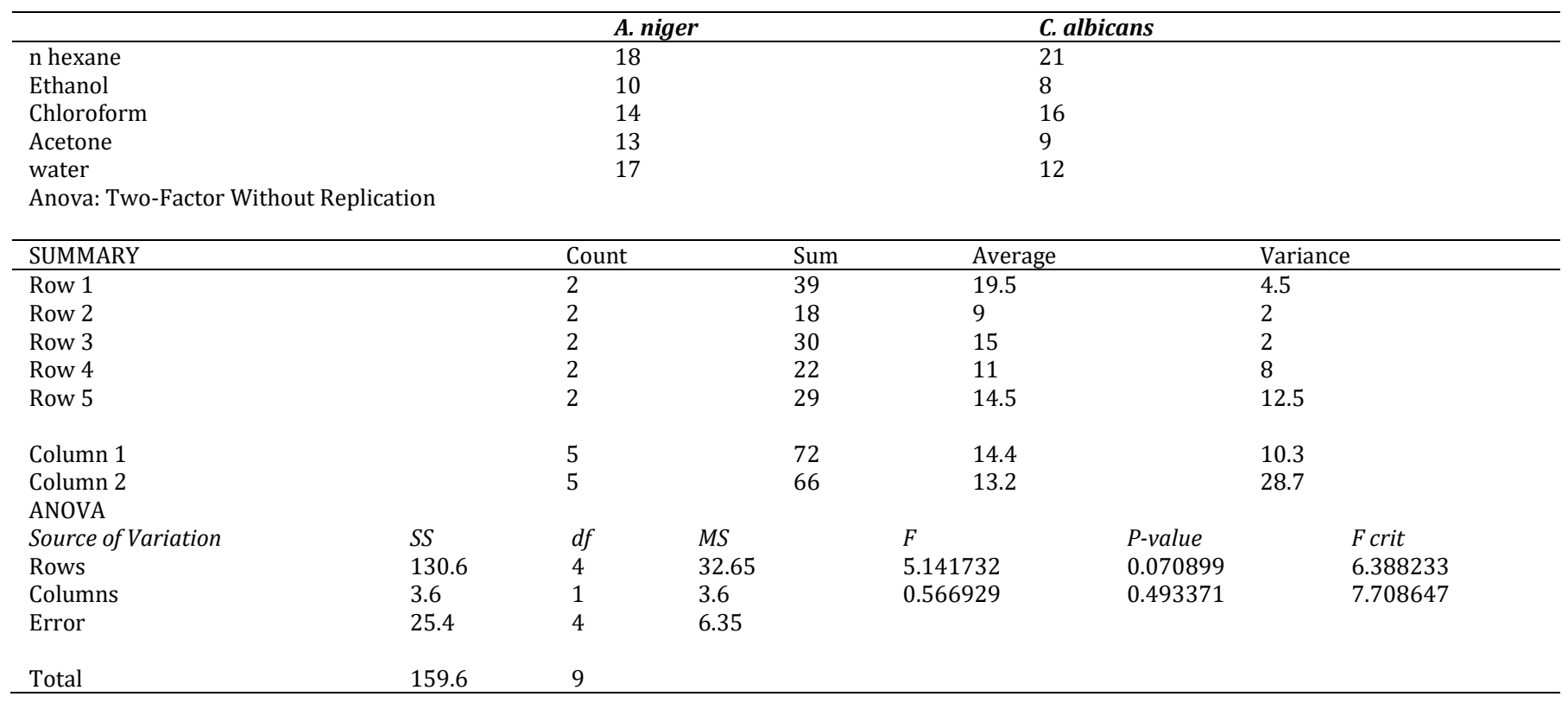


Table 6: Statistical analysis antifungal activity of solvent extract (50 micro gram/ml)

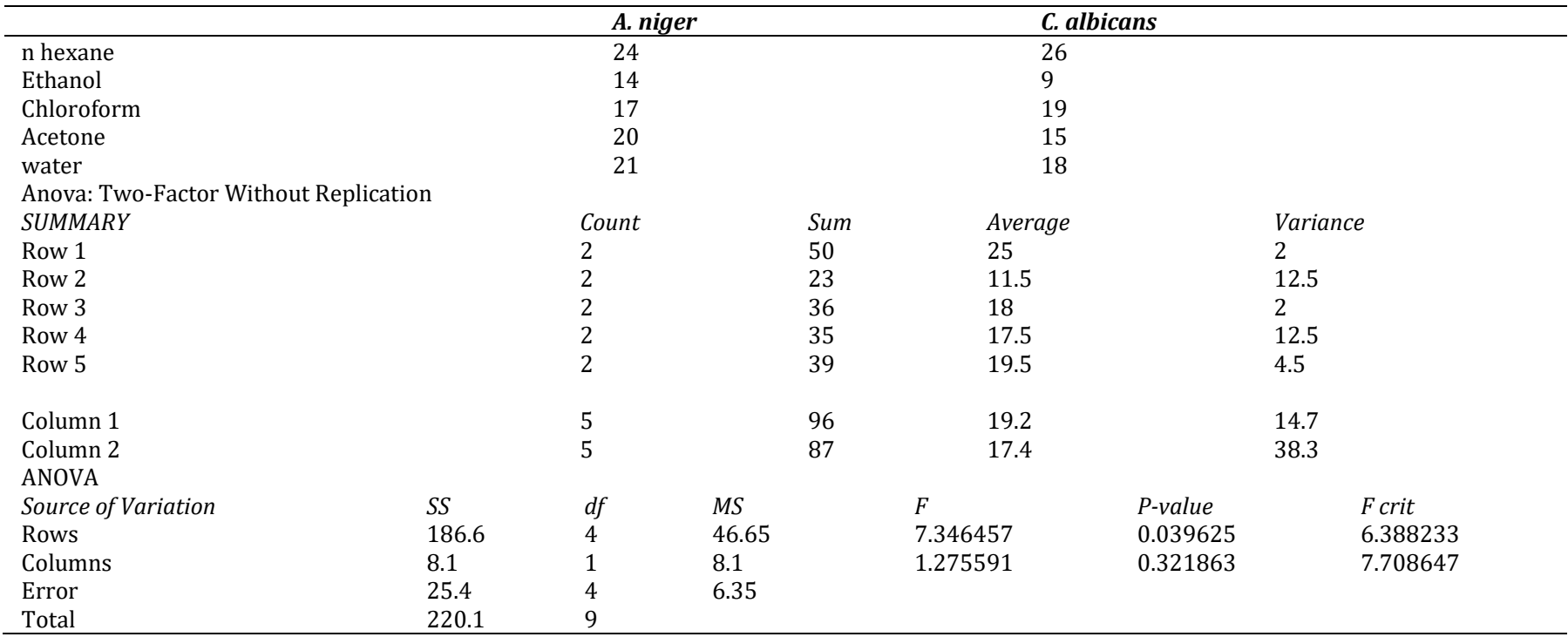

Different organic solvents extracts have different phytoconstituents in different amounts and that is why there is differential inhibition of the bacterial and fungal strains. As for the solvents, the n-hexane extract had the best inhibitory effect among five solvents tested (n-hexane, ethanol, chloroform, acetone and water). The MIC for $\mathrm{n}$-hexane was $1.6 \mu \mathrm{g} / \mathrm{ml}$ for $S$. aureus (tables 7) leading to a conclusion that the n-hexane extract was found to be the most potent among all extracts.

Table 7: Extract MIC of test microorganisms

\begin{tabular}{lllll}
\hline Microorganisms & n-hexane & Ethanol & chloroform & Acetone \\
\hline S. aureus & 1.6 & 3.12 & 12.5 & 12.5 \\
B. subtilis & 3.12 & 12.5 & 25 & 3.12 \\
P. aeruginosa & 3.12 & 12.5 & 12.5 & 25 \\
E. coli & 3.12 & 25 & 3.12 & 12.5 \\
S. typhimurium & 12.5 & 12.5 & 3.12 & 25 \\
A. niger & 3.12 & 12.5 & 25 & 25 \\
C. albicans & 3.12 & 3.12 & 3.12 & 25 \\
\end{tabular}

\section{DISCUSSION}

In last few years, there has been a dramatic rise in search for natural products with antimicrobial properties because they offer a hope to find new drugs or drug leads which have a promising antimicrobial activity with lesser side effects to human beings.

The results of phytochemical screening of leaves and aerial parts of C. tomentosa revealed the presence of active phytoconstituents such as alkaloids, glycosides, steroids, saponins, flavonoids, terpenoids and tannins etc [12].

According to previous studies, it was found that roots were having better antimicrobial potential as compared to other parts of the plant [7].
Out of these phytoconstituents, flavonoids are one of the largest group of phenolic compounds, numerous reports support their use as a primary antioxidant and possess antimicrobial, anti-inflammatory, anti-allergic, anticancer activities etc [13]. Saponins are a special class of glycosides which have soapy characteristics and possess antibacterial, hypolipidemic, antidiabetic, and anticancer activity [16] Plant-derived alkaloids are the biggest class of phytochemical and exhibit many therapeutic effects like antioxidant, analgesics, muscle relaxant, antibiotics, anticancer and also responsible for antiprotozoal, cytotoxic and antimicrobial properties $[14,15]$.

The presence of secondary metabolites including alkaloids, saponins, flavonoids in the plant may be are responsible for its potential antibacterial activity [17].

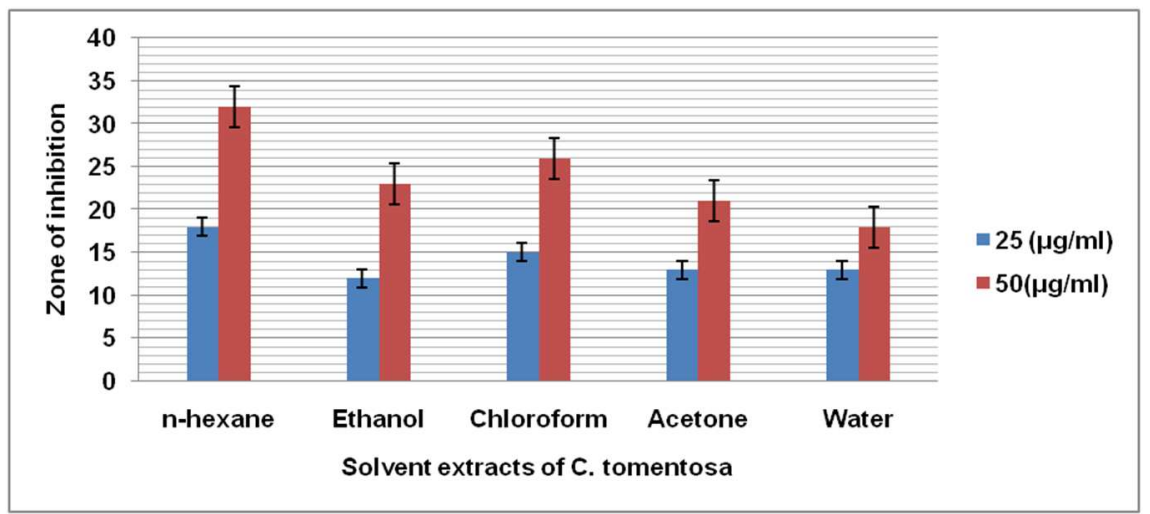

Fig. 1: Comparison of antibacterial activity of different solvent extracts against $S$. aureus and the values are expressed as mean \pm SEM; $n=3$ 


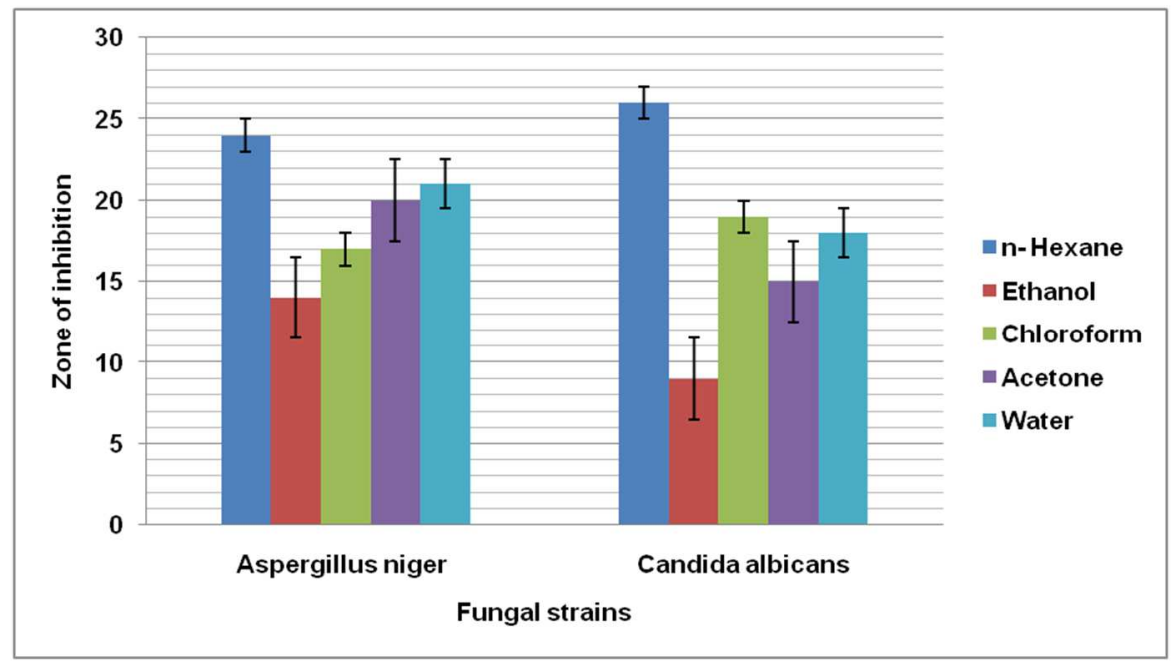

Fig. 2: Comparison of antifungal activity of different solvent extracts and the values are expressed as mean $\pm S E M$; $n=3$

The reason for a greater activity of hexane extract could be attributed to the non-polar nature of the solvent which may be responsible for the extraction of a wide range of phytoconstituents that potentiates the activity of extract [18]. Thus, the greater the phytochemical load, the greater the activity of a plant extract.

On correlating the results an inference can be drawn that presence of the majority of phytochemicals and large quality of non-polar compounds in hexane extract may be responsible for its prominent activity against all the bacterial and fungal strain. The present study not only suggests the strong antimicrobial potential of $C$. tomentosa roots, but also suggests that extracting solvent plays a crucial role for evaluating the antimicrobial activity of medicinal plants.

\section{CONCLUSION}

The results of this study revealed a correlation between traditional therapeutic use and the in vitro antibacterial activity, a broad spectrum anti-microbial activity of root extract of $C$. tomentosa extracts against both Gram-positive, Gram-negative bacteria as well as fungi, with variable degrees of sensitivity. Many phytochemical investigations carried on the rhizomes and roots of $C$. tomentosa had led to the steroids, triterpenoids, alkaloids, fats, sterols, and phytol. The above antimicrobial activity may be attributed to the presence of these bioactive constituents.

More importantly, the results indicated that n-hexane extract of $C$. tomentosa was more effective against $S$. aureus followed by chloroform, ethanol, acetone and water extracts, respectively. More work on the antimicrobial activity of this and similar such extracts can be instrumental in discovery and development of novel lead bioactive molecules from natural products

The above activity has been reported for the first time of the roots $C$. tomentosa.

\section{ACKNOWLEDGMENT}

The authors are grateful to the authorities of P. E. S's Rajaram and Tarabai Bandekar College of Pharmacy, Ponda-Goa for encouraging and providing necessary laboratory facilities. Thanks are also due to NCL Pune, India for providing bacterial and fungal strains. We also thank Professor G. I. Hukkeri, Associate Professor in Botany, Dhempe College of Arts and Science, Miramar, Panaji, for authenticating and providing the plant specimen for the study.

\section{AUTHORS CONTRIBUTIONS}

Ms. Gauri Pai Angle corresponding author for this publication, working as Assistant Professor has designed the study, performed the experiments, interpreted the results and worked on the manuscript; Dr. Yogita Sardessai has guided the study and co-wrote the paper. Both authors have discussed the results and written the manuscript.

\section{CONFLICT OF INTERESTS}

Authors declare no conflict of interest

\section{REFERENCES}

1. Li Xia, Qiang Guo, Pengfei Tu, Xingyun Chai. The genus casearia: a phytochemical and pharmacological overview. Phytochem Rev 2015;14:99-135.

2. Rao KT, Sreedevi K, Veerabhadrappa A, Chetty MK. Indian Journal of Plant Sciences; 2014;3:136-44.

3. Adhikari BS, Babu MM, Saklani PL, Rawat GS. Ethnobotanical Leaflets; 2010;14:46-83.

4. Anbukkarasi M, Dhamotharan R, Janarthanam B. Studies on phytochemical screening, tannins content and antibacterial activity from leaf and callus extracts of memecylon umbellatum. Asian J Pharm Clin Res 2017;10:265-9.

5. Tyagi R, Shukla A, Shukla RK. Phytochemical screening and pharmacological evaluation of different extracts of plant casearia tomentosa leaves. Int J Pharm Pharm Sci 2017;9:166-71.

6. Aljuraifani A. Impact of solvent types on antimicrobial activities of pumpkin extracts. Asian Int J Life Sci 2017;26:230-5.

7. Pai Angle G, Sardessai Y. Screening of antimicrobial activity of caesaria tomentosa. World J Pharma Res 2017;6:778-85.

8. Kumar S, Kamraj M. Antimicrobial activity of Cucumis anguria L. By agar well diffusion method. Bot Res Int 2011;4:41-2.

9. Farrukh R, Zargar MA, Akhtar A, Tasduq SA. Antibacterial and Antifungal activity of Thymus sepeyllum. Bot Res Int 2012;5:36-9.

10. GbadamosiI T. Evaluation of antibacterial activity of six Ethnobotanicals used in the treatment of Infectious diseases in Nigeria. Bot Res Int 2012;5:83-9.

11. Harsha VS. In vitro antibacterial activity of Amaranthus spinosus root extracts. Pharmacophore 2011;2:266-70.

12. Shukla A, Tyagi R, Vats S. Total phenolic content, antioxidant activity and phytochemical screening of hydroalcoholic extract of Casearia tomentosa leaves. J Chem Pharma Res 2016;8:136-41.

13. A Kar. Pharmaocgnosy and pharmacobiotechnology, New Delhi, New Age International Limted Publishers; 2007. p. 330-41.

14. Nagalinga S, Sasikumar CS, Cherian KM. Extraction and phytochemical screening of active compounds. Asian J Pharm Clin Res 2012;5:179-81.

15. Shukla A, Vats S, Shukla RK. Proximate composition, nutritive value and evaluation of antioxidant potential of stem of Dracaena reflexa Lam. Int J Pharm Sci 2014;6:360-4.

16. Malu SP, Obochi GO, Edem CA. Effect of method of extraction on phytochemical constituents and antibacterial properties of tetracarpidium conophorum Seeds. Global J Pure Appl Sci 2009;15:373-6. 
17. Tyagi R, Shukla A, Shukla RK. Phytochemical screening and pharmacological evaluation of different extracts of plant casearia tomentosa leaves. Int J Pharm Pharm Sci 2017;9:16671.
18. Banerjee S, Kaushik S, Singh Tomar R. Effect of different solvents on antioxidant activity of leaf extracts of calotropis procera and azadirachta indica. Asian J Pharm Clin Res 2017;10:268-72. 